\title{
Comparison of CA-125, conventional ultrasound and CT imaging in diagnosis and staging of ovarian cancer correlated with surgico-pathological findings
}

\section{Nilufer Moideen, Shripad S. Hebbar*, Lavanya Rai, Shyamala Guruvare, Prashant Adiga}

Department of Obstetrics \& Gynaecology, Kasturba Medical College, Manipal University, Udupi-576104, Karnataka, India

Received: 27 August 2014

Accepted: 19 September 2014

\section{*Correspondence:}

Dr. Shripad S. Hebbar,

E-mail: drshripadhebbar@yahoo.co.in

Copyright: $($ the author(s), publisher and licensee Medip Academy. This is an open-access article distributed under the terms of the Creative Commons Attribution Non-Commercial License, which permits unrestricted non-commercial use, distribution, and reproduction in any medium, provided the original work is properly cited.

\begin{abstract}
Background: Preoperative evaluation of suspected ovarian malignancy is of paramount importance and a diagnostic tool with high degree of precision helps treating physician in planning appropriate surgery and also neoadjuvant chemo therapy in candidates who are not currently fit for extensive surgical procedure. Though the ultrasound examination of abdomen and pelvis helps one in detection and characterization of adnexal lesion to some extent, its diagnostic ability is further improved by addition of advanced imaging techniques such as computed tomography, magnetic resonance imaging and thus can prove beneficial in choosing patient for right surgery, there by optimising the treatment outcome. Objective of current study was to compare ultrasonography imaging, CT imaging, CA-125 values, RMI 3 score, surgical staging and histopathological findings in carcinoma ovary.

Methods: The study is a prospective observational study, carried out between September 2011 and July 2013, in the department of obstetrics and gynaecology, Kasturba hospital, Manipal. All cases of carcinoma ovary who underwent imaging (USG, CT/ MRI) were followed by staging laparotomy during the course of study. All cases of carcinoma ovary who has undergone neoadjuvant chemotherapy were excluded. All patients included in the study underwent CA-125 estimation, conventional ultrasound, CT scan (Sixty four slice with contrast) followed by staging laparotomy and histopathological examination of the specimen. RMI-3 (Risk Malignancy Index Score-3) was calculated in all cases.

Results: 54 patients were included in the evaluation. The efficacy of CT (Sensitivity 95.1\%, specificity 46.2\%) and Ultrasound (Sensitivity $90.2 \%$, specificity $53.8 \%$ ) were comparable in detection of ovarian malignancy. Combination of CT and USG (Sensitivity 95\%, specificity 78.6\%) gave the best result in non-invasive investigations whereas combination of CT and surgical staging (Sensitivity 95.1\%, specificity 84.6\%) gave a better result when invasive modalities were considered. RMI-3 score had sensitivity of $82 \%$ and specificity of $64 \%$ and did not improve the accuracy.

Conclusions: Optimal preoperative evaluation was achieved with combination of USG and CT. Additional of CA125 further improved the precision. All the three modes had good diagnostic performances, and complimented each other in further refining the characterization of the mass, local spread and distant tumour dissemination.
\end{abstract}

Keywords: Ovarian cancer, Ultrasound, CT, RMI-3, Surgical staging

\section{INTRODUCTION}

Ovarian cancer is one of the leading cancers in Indian women. ${ }^{1}$ In year 2012, ovarian cancer occurred in 239000 women worldwide (new 26834 cases in India) and resulted in 152000 deaths (GLOBOCAN 2012). ${ }^{2}$ Ovarian cancer is more lethal than endometrial and cervical cancer combined due to delayed diagnosis. Owing to the lack of symptoms and early peritoneal dissemination, the tumour has spread outside the pelvis in approximately 
$70 \%$ of cases at the time of diagnosis. ${ }^{3}$ The stage at diagnosis is the most important prognostic factor. The 5year survival rates drop from $93 \%$ in patients with localized disease to $28 \%$ in those with distant metastases.

CA-125 which has been found to be elevated in epithelial cancer is more often nonspecific, and gynaecological examination and ultrasound evaluation too have low sensitivity, CT and MRI imaging have become the popular method of detection and preoperative assessment of ovarian tumours. ${ }^{4}$

Proper pre-operative staging by imaging can prevent unnecessary surgeries in case of advanced cases of ovarian carcinoma which leads to morbidity which is preventable. Accurate staging using imaging helps to decide on neoadjuvant chemotherapy which will be ideal for patients with advanced carcinoma which helps in optimal tumour debulking during interval cytoreductive surgeries.

Whenever an ovarian mass is detected by clinical examination, the next task is to determine the malignant nature of the disease and its spread within pelvis and abdominal cavity. Establishing benign nature of the lesion preoperatively may reduce unnecessary ultraradical surgery, thereby reducing morbidity and mortality related to prolonged and extensive staging procedure. Hence it is important that diagnostic studies should assist the gynae oncologist in planning appropriate surgery and chemotherapeutic planning.

Introduction of high frequency transvaginal probe (more than $5 \mathrm{mHZ}$ ) has greatly improved the ultrasound capability in characterization of adnexal masses, as the images obtained are of high resolution and clarity. Preoperative evaluation by Computed Tomography (CT) with contrast enhancement, till today is one of the best method available to characterize the ovarian mass and to determine its extent of spread and CT findings match with surgico-pathological staging in 70 to $90 \%$ of cases. ${ }^{5}$

Only one study has compared the efficiency of all the three imaging modalities in the staging of ovarian cancer, the study was conducted by the RDOG (Radiology Diagnostic Oncology Group). ${ }^{6}$ Though ultrasound is an important tool in evaluating nature of the tumour, it cannot assess tumour spread. CT and MRI imaging modalities score over ultrasound in this aspect, especially for assessing the lesions underneath diaphragm, on hepatic surfaces and evaluation of intrahepatic small lesions and involvement of lesser sac. Also lymph node metastasis (smaller than $1 \mathrm{~cm}$ ) are easily picked by $\mathrm{CT}$ and even better by MRI. ${ }^{7}$

According to American College of Radiology (ACR) appropriateness criteria reviewed in 2012 for staging and follow-up of ovarian cancer in pre-treatment staging of ovarian cancer as well as to rule out recurrent ovarian cancer, CT abdomen and pelvis with contrast again holds the highest ranking followed by MRI with or without contrast. $^{8}$

The aim of our study was to compare ultrasonography imaging, CT imaging, CA-125 values, RMI 3 score, surgical staging and histopathological findings in carcinoma ovary.

\section{METHODS}

The present study is a prospective observational study, carried out between September 2011 and July 2013, in the department of obstetrics and gynaecology, Kasturba hospital, Manipal, after obtaining the institutional ethical committee clearance (IEC 242/2011, dated 15-09-2011).

\section{Inclusion criteria}

All cases of Carcinoma ovary who underwent imaging (USG, CT/MRI) followed by staging laparotomy during the course of study.

\section{Exclusion criteria}

All cases of carcinoma ovary who have undergone neoadjuvant chemotherapy.

\section{Sample size calculation}

Calculated sensitivity of the ultrasound for the detection of ovarian carcinoma is around $85 \%$ (Jung et al. 2002). ${ }^{9}$ The minimum required sample size is determined by Buderer's formula;

$$
\mathrm{N}=\left[\mathrm{Z}_{1-\alpha / 2 \times}^{2} \mathrm{P} \times(1-\mathrm{P})\right] / \mathrm{L}^{2}
$$

Where; in: $\mathrm{n}=$ number of patients, $\mathrm{Z}_{1-\alpha / 2}=1.96$ (standard normal deviate value that divides the central $95 \%$ of $\mathrm{z}$ distribution from $5 \%$ in the tails), $\mathrm{P}=$ the reported sensitivity ( $85 \%$, i.e., 0.85$), \mathrm{L}=$ absolute precision desired on either side (half width of the confidence interval of the confidence interval) of sensitivity (10\% i.e., 0.1$)$.

Accordingly we got the minimum sample size as 49 and we have recruited 54 cases taking into consideration some dropouts.

All patients included in the study underwent cancer antigen-125 estimation (CA-125 Detected by Immunohistochemistry), conventional ultrasound (Toshiba Nimio ultrasound machine with frequency $6.5 \mathrm{MHz}$ transvaginal transducer and $5 \mathrm{MHz}$ transabdominal transducer), CT scan (Brilliance 64 by Philips, sixty four slice CT with contrast) followed by staging laparotomy (same standard technique in all cases) and histopathological examination of the specimen. RMI3 was calculated in all cases, which was given by the equation;

RMI 3 = U×M×CA-125 
Where; a total ultrasound score of 0 or 1 made $U=1$, and a score of $\geq 2$ made $U=3$; premenopausal status made $\mathrm{M}=1$ and postmenopausal $\mathrm{M}=3$. The score for $\mathrm{CA}-125$ remains unchanged (corresponds to actual level of serum concentration in units $/ \mathrm{mL}$ ). Ultrasound features (one point for each finding) suggesting malignancy were multilocular cyst, solid areas, bilateral lesions, ascites, intra-abdominal metastases. RMI score of more than 200 was considered to represent malignancy. ${ }^{10}$

\section{Statistical analysis}

Statistical Package for the Social Sciences (SPSS-16) was used for statistical compilation and analysis.

\section{RESULTS}

Total of 68 patients were included in the study of which 11 underwent neoadjuvant chemotherapy and 3 deferred treatment.

Remaining 54 patients were included in the study.

The youngest patient was 11 years and the most elderly patient was 73 years, mean age \pm standard deviation was calculated which $47.5 \pm$ was 15.5 years.

Majority of patients included were above 40 years. Only 9 patients were in the less than 40 years group. Table 1 shows patient demographic details.

Table 1: Parity and menopausal status of patients studied.

\begin{tabular}{|llllll|}
\hline Parity & $\begin{array}{l}\text { Number } \\
(\%)\end{array}$ & $\begin{array}{l}\text { Pre-menopausal } \\
\mathrm{n}(\%)\end{array}$ & $\begin{array}{l}\text { Menopausal } \\
\text { s years n }(\%)\end{array}$ & $\begin{array}{l}\text { Menopausal } \\
\text { 6-10 years n }(\%)\end{array}$ & $\begin{array}{l}\text { Menopausal } \\
\geq 11 \text { years } n(\%)\end{array}$ \\
\hline Nulliparous & $10(18.5)$ & $6(11.1)$ & $3(5.5)$ & - & $1(0.18)$ \\
\hline Multiparous & $38(70.3)$ & $16(29.6)$ & $6(11.1)$ & $9(16.6)$ & $7(12.9)$ \\
\hline Grand multi & $6(11.1)$ & - & $2(3.7)$ & $1(0.18)$ & $3(5.5)$ \\
\hline
\end{tabular}

Majority of patients were multiparious (38 cases) and were in surprisingly in premenopausal age group (16 cases) with commonest presenting complain being abdominal complaints including post meal distention of abdomen, loss of appetite and lower abdomen pain (Table 2).

Table 2: Presenting complaints of patients in the study.

\begin{tabular}{|ll|}
\hline Chief complaints & $\mathrm{n}(\%)$ \\
\hline $\begin{array}{l}\text { Abdominal complaints (post meal } \\
\text { distension, loss of appetite, lower } \\
\text { abdomen pain) }\end{array}$ & $42(77.7)$ \\
\hline Post-menopausal bleeding & $7(12.9)$ \\
\hline Menstrual complaints & $2(3.7)$ \\
\hline No complaints (incidental finding) & $3(5.5)$ \\
\hline
\end{tabular}

Ca 125 levels were low (<35 U/ml) in $15(27.7 \%)$, mildly elevated $(35-200 \mathrm{U} / \mathrm{ml})$ in $18(33.3 \%)$, significantly elevated in $(201-1000 \mathrm{U} / \mathrm{ml})$ in $18(33.3 \%)$ and were very high $(>1001 \mathrm{U} / \mathrm{ml})$ in $3(5.5 \%)$ cases.

The histopathological analysis of surgical resected specimens was considered as gold standard for comparison of diagnostic values of various investigative modalities (Table 3 ).

Diagnostic comparison was done (Table 4) for different modes of evaluation using sensitivity, specificity, Positive Predictive Value (PPV), Negative Predictive Value (NPV) and accuracy.
Table 3: Histopathological findings in 54 patients who underwent surgery with suspicion of ovarian tumour.

\begin{tabular}{|c|c|c|c|}
\hline $\begin{array}{l}\text { Nature } \\
\text { of the } \\
\text { disease }\end{array}$ & $\begin{array}{l}\text { WHO } \\
\text { group }\end{array}$ & Histopathology & $\mathbf{N}$ \\
\hline \multirow{3}{*}{ Benign } & \multirow{3}{*}{ Epithelial } & Serous cystadenoma & 1 \\
\hline & & Mucinous cystadenoma & 7 \\
\hline & & $\begin{array}{l}\text { Mucinouscystadenoma with } \\
\text { Brenner }\end{array}$ & 1 \\
\hline \multirow{2}{*}{$\begin{array}{l}\text { Border- } \\
\text { line }\end{array}$} & \multirow{2}{*}{ Epithelial } & Borderline mucinous & 5 \\
\hline & & Borderline serous & 1 \\
\hline \multirow{13}{*}{$\begin{array}{l}\text { Malig- } \\
\text { nant }\end{array}$} & \multirow{6}{*}{ Epithelial } & Serous cystadeno carcinoma & 12 \\
\hline & & Mucinous cystadeno carcinoma & 1 \\
\hline & & Clear cell Carcinoma & 3 \\
\hline & & Endometrioid adenocarcinoma & 5 \\
\hline & & Adenocarcinoma & 2 \\
\hline & & Adenofibroma & 1 \\
\hline & \multirow{4}{*}{ Germ cell } & $\begin{array}{l}\text { Yolk sactumor ( } 1 \text { with hepatoid } \\
\text { differentiation) }\end{array}$ & 3 \\
\hline & & Ovarian dysgerminoma & 2 \\
\hline & & Immature teratoma & 1 \\
\hline & & $\begin{array}{l}\text { Malignant mixed Mullerian } \\
\text { tumour }\end{array}$ & 2 \\
\hline & \multirow{2}{*}{ Metastatic } & Krukenberg tumor & 2 \\
\hline & & Fallopian tube $\mathrm{Ca}$ & 1 \\
\hline & $\begin{array}{l}\text { Transition } \\
\text {-al cell }\end{array}$ & Transitional cell carcinoma & 1 \\
\hline \multirow{3}{*}{ Others } & & Endometriotic cyst & 1 \\
\hline & & Pendunculated fibroid & 1 \\
\hline & & Paraovarian cyst & 1 \\
\hline
\end{tabular}


Table 4: Diagnostic performance of USG, CT and surgical staging in evaluation of ovarian tumours.

\begin{tabular}{|c|c|c|c|c|c|}
\hline & Sensitivity (\%) & Specificity (\%) & PPV $(\%)$ & NPV $(\%)$ & Accuracy $(\%)$ \\
\hline \multicolumn{6}{|c|}{ A. Detection unilaterality/bilaterality } \\
\hline USG & 55.5 & 55.58 & 55.5 & 44.4 & 55 \\
\hline $\mathrm{CT}$ & 81.4 & 51.8 & 62.85 & 73.6 & 67 \\
\hline Surgical staging & 85.1 & 85.1 & 85.1 & 14.81 & 85 \\
\hline \multicolumn{6}{|c|}{ B. Detection of malignant ascites } \\
\hline USG & 66.6 & 64.1 & 35.7 & 16.6 & 60 \\
\hline CT & 87.5 & 50 & 42.4 & 90.4 & 61 \\
\hline Surgical staging & 80 & 46.1 & 36.3 & 85.7 & 56 \\
\hline \multicolumn{6}{|c|}{ C. Detection of lymph node metastasis* } \\
\hline CT & 81.8 & 67.4 & 39.1 & 93.5 & 70 \\
\hline Surgical staging & 83.3 & 83.3 & 58.8 & 94.59 & 83 \\
\hline \multicolumn{6}{|c|}{ D. Detection of Peritoneal Metastasis } \\
\hline USG & 33.3 & 93.9 & 77.7 & 68.8 & 70 \\
\hline CT & 68.1 & 87.5 & 78.9 & 80 & 80 \\
\hline Surgical staging & 100 & 87.8 & 84 & 100 & 93 \\
\hline
\end{tabular}

CT showed a $67 \%$ accuracy compared to $55 \%$ by USG in detection of ovarian tumours whether unilateral or bilateral involvement. Accuracy of both USG and CT were similar; $60 \%$ and $61 \%$ respectively in detection of malignant ascites. $\mathrm{CT}$ had a $68 \%$ sensitivity in detecting peritoneal metastases than USG $(33 \%)$ and hence preferred for preoperative staging. Both USG and CT had equal accuracy in detection of hepatic metastasis. Overall accuracy of CT in staging ovarian tumors was $95 \%$ compared to USG which was only $82 \%$. The efficacy of different modalities in detecting a malignant ovarian cancer was better when combined (Table 5). When two parameters were compared the combination of CT and surgical staging gave the highest results, next to combination of USG and surgical staging. The usual investigative modality (USG + CA-125) gave only a comparable result to $\mathrm{CT}$ alone in detecting ovarian malignancy.

Table 5: Diagnostic values of single parameter vs. two parameters.

\begin{tabular}{|llllll|}
\hline & Sensitivity $(\%)$ & Specificity $(\%)$ & PPV (\%) & NPV $(\%)$ & Accuracy $(\%)$ \\
\hline A. Single parameter & \multicolumn{5}{l}{} \\
\hline CA 125 $(>35 \mathrm{u} / \mathrm{ml})$ & 87.8 & 76.9 & 92.3 & 66.7 & 85.2 \\
\hline USG & 90.2 & 53.8 & 86 & 63.6 & 81.5 \\
\hline CT & 95.1 & 46.2 & 84.8 & 75 & 83.3 \\
\hline Surgical staging & 92.7 & 100 & 100 & 81.3 & 94.4 \\
\hline B. Two parameters & & & & \\
\hline CA 125 \& USG & 92.7 & 76.9 & 92.7 & 76.9 & 88.9 \\
\hline CA 125 \& CT & 92.9 & 75 & 92.9 & 75 & 88.9 \\
\hline USG \& CT & 95 & 78.6 & 92.7 & 84.6 & 90.7 \\
\hline USG \& surgical staging & 95.1 & 84.6 & 95.1 & 84.6 & 92.6 \\
\hline CT \& surgical staging & 97.6 & 91.7 & 97.6 & 91.7 & 96.3 \\
\hline RMI 3 score* & 82 & 64 & 87 & 56 & 77.7 \\
\hline *RMI 3 scores include menopausal state in addition to CA 125 and USG findings & & \\
\hline
\end{tabular}

In our study, both USG and CT showed remarkable accuracy for detection of extraovarian spread individually and also when combined together.
CT had better specificity in diagnosing malignant ovarian mass and better accuracy in pre-operative staging of the disease compared to ultrasound imaging. 


\section{DISCUSSION}

This prospective study evaluated various modalities of investigations in ovarian masses mainly to determine malignant nature, extent of local tumour spread and extraovarian dissemination. The diagnostic abilities of each was analysed and correlated with one another, considering final histopathological report as gold standard. The results indicated that combined parameters were superior in detection of ovarian malignancy and its spread than individual modalities taken independently.

The percentage of stage 3 and 4 disease were high, almost $60 \%$. This result was likely due to the referral status of our center which is a tertiary center.

Regarding the role of ultrasound in evaluation of adnexal lesion, our aim was not to evaluate its role for routine screening for malignancy, but to study indicators of malignancy such as thick walls, thick septae, intracystic projections, solid areas, bilaterality, presence of ascites and intra-abdominal metastasis, so that we could estimate RMI scores accurately. We also estimated CA-125 levels in all the cases, though we knew that this marker is primarily meant for tumors of epithelial origin which constitutes the majority of ovarian tumours (up to $80 \%$ ). However CA-125 is not very specific for ovarian cancer and it is well-known that false positive results may result from several benign conditions such as pelvic inflammation, endometriosis, adenomyosis, uterine fibroids and even normal menstruation. ${ }^{11}$

We calculated RMI-3 for all our cases and compared it to combined results of USG and Ca-125 and obtained an accuracy of $77.7 \%$ for RMI-3 in detection of ovarian malignancy which was far lower than accuracy of combined parameter USG and $\mathrm{Ca}-125$ which was $88.9 \% .{ }^{12}$ The efficacy of RMI scores alone in detection of a malignant ovarian tumour is less, hence other investigative modalities results should also be considered in addition to RMI.

Table 6: Comparison of studies on USG for detection of ovarian malignancy*.

\begin{tabular}{|lll|}
\hline Studies & $\begin{array}{l}\text { Sensitivity } \\
(\%)\end{array}$ & $\begin{array}{l}\text { Specificity } \\
(\%)\end{array}$ \\
\hline Liu J et al. $(2007)^{13}$ & 89 & 84 \\
\hline Fatma Ferda $(2007)^{14}$ & 83 & 92 \\
\hline${\text { UKCTOS }(2009)^{15}}^{15}$ & 89 & 99 \\
\hline Firoozabadi et al. $(2011)^{16}$ & 52 & 88 \\
\hline IOTA (2012) $^{17}$ & 90 & 88 \\
\hline Hafeez S et al. (2013) $)^{18}$ & 91 & 91 \\
\hline Current study (2013) & 90 & 54 \\
\hline
\end{tabular}

Our results of USG compared to other studies in literature (Table 6) showed a comparable sensitivity of $90 \%$ especially when compared to the results of international ovarian tumor association and United Kingdom Collaborative Trial of Ovarian Cancer Screening
(UKCTOS) in detection of ovarian malignancy. ${ }^{13}$ Our study showed a very low specificity of $54 \%$ in detection of ovarian carcinoma when compared to other studies in literature. This may be because of the inter-observer variation in results of ultrasonography and also the failure of USG in assessment of the involvement of retroperitoneal area.

The results of CT in our study compared to other studies in literature (Table 7) showed a higher sensitivity, comparable to the study by Mubarak et al. ${ }^{19}$ Although our study showed a very low specificity of $46 \%$ because of the high number of false positives which may be due to non-specific inflammatory changes within the tumour, reactive lymphadenitis appearing as enlarged lymph nodes on CT, which were reported as possible malignancy, which changes the stage of disease. And also lack of extensive retroperitoneal and paraaortic lymph node dissection also would have contributed to the low specificity.

Table 7: Comparison of studies on CT for detection of ovarian malignancy.

\begin{tabular}{|lll|}
\hline Studies & $\begin{array}{l}\text { Sensitivity } \\
(\%)\end{array}$ & $\begin{array}{l}\text { Specificity } \\
(\%)\end{array}$ \\
\hline Kurtz et al. $(1999)^{20}$ & 90 & 88 \\
\hline Kinkel et al. $(2005)^{21}$ & 81 & 87 \\
\hline Liu J et al. $(2007)^{13}$ & 85 & 86 \\
\hline Fatma Ferda $(2007)^{14}$ & 91 & 96 \\
\hline Mubarak et al. $(2011)^{19}$ & 97 & 91 \\
\hline Firoozabadi et al. $(2011)^{16}$ & 79 & 92 \\
\hline Current study & 95 & 46 \\
\hline
\end{tabular}

NICE clinical bulletin (no. 122) ${ }^{14}$ states that whenever clinical feature, ultrasound and serum CA-125 prompt the diagnosis of ovarian cancer, then the recommendation is to do abdomino-pelvic CT or MRI to document the pelvic and peritoneal spread and thorax should be included in the imaging if patient has respiratory findings, for example plural effusion, decreased air entry etc. ${ }^{22}$ In our study, we could get a better sensitivity $95 \%$ and specificity $78.6 \%$ when ultrasound and CT were combined.

Our study showed that efficacy of different modalities in detecting a malignant ovarian cancer was better when combined. When two parameters were compared the combination of CT and surgical staging gave the highest results, accuracy of $96.3 \%$ next to combination of USG and surgical staging $92.3 \%$.

Based on our findings where we had a significant better results in staging laparotomy (Sensitivity 92.7\%, specificity $100.0 \%$ ) in detection of both ovarian carcinoma and its spread to other sites, hepatic metastasis (Sensitivity $100 \%$, specificity $98.03 \%$ ), lymph node metastasis (Sensitivity 83.3\%, Specificity 83.3\%), peritoneal metastasis (Sensitivity 100\%, specificity 
$87.8 \%$ ), which lead us to conclude that patients with negative findings on imaging should continue to undergo staging laparotomy as this procedure add only minimal morbidity and operative time and result in the upstaging of a significant percentage of patients. We believe that comprehensive surgical staging remains a critical aspect in the evaluation of patients with apparent early-stage ovarian cancer, as this procedure aids in identifying patients who may benefit from adjuvant chemotherapy.

\section{CONCLUSION}

The results of present study indicate remarkable diagnostic abilities of two different imaging (USG \& CT) modalities in detection of extent of malignant spread both individually and in combination. Addition of the third parameter (CA-125) further improves the precision. It is difficult to suggest a single investigative modality for evaluation of women with suspected ovarian malignancy. All the three modes, though not inferior by themselves, are complimentary to each other in their diagnostic performances.

Pre- operative sonography by both routes should be performed, transvaginal ultrasound provides opportunity for characterisation of ovarian mass, transabdominal ultrasound imaging assesses extra pelvic dissemination. CT imaging augments ultrasound findings because of its ability to image the deeper areas and the minimal extra ovarian spread and proves to be important adjunct to assess and treat when surgical staging is not feasible (by neoadjuvant chemotherapy). However, in cases where patient cannot afford CT imaging, a combination of CA 125 and USG can be considered satisfactory in preoperative evaluation of ovarian carcinoma.

\section{Limitations}

The reports of ultrasonography and CT were not double blinded during reporting. Detection of distant metastasis was not possible for complete staging as all patients did not undergo CT/USG of chest or brain because of financial constraints. The prognosis, overall survival rate and progression free interval needs to be calculated to comment regarding the benefit of complete pre op staging and laparotomy.

\section{ACKNOWLEDGEMENTS}

Authors would like to thank Dr. Pratap Kumar, head of unit 1, Dr. Murlidhar V. Pai, head of unit 2, Dr. Jyothi Shetty, head of unit 4, Dr. Sapna Amin, head of unit 5, Dr. Satadru Ray, head of surgical oncology for allowing some of their patients for participating in the study.

\section{Funding: No funding sources}

Conflict of interest: None declared

Ethical approval: The study was approved by the institutional ethics committee (IEC 242/2011, dated 1509-2011).

\section{REFERENCES}

1. Basu P, De P, Mandal S, Ray K, Biswas J. Study of 'patterns of care' of ovarian cancer patients in a specialized cancer institute in Kolkata, eastern India. Indian J Cancer. 2009;46:28-33.

2. GLOBOCAN 2012. Estimated cancer incidence, mortality and prevalence in 2012. World Health Organization. International Agency for Research on Cancer. 2012. Available at: http://globocan.iarc.fr. Accessed 25 August 2014.

3. Anish Bali, Karina R. Eynolds. The current management of primary ovarian cancer: a review. Cancer Ther. 2002;2:305-16.

4. Garner EI, Garrett AP, Berkowitz RS. Natural history and detection of ovarian carcinoma. Glob Libr Women's Med. 2008; DOI 10.3843/GLOWM.10246.

5. Forstner R, Hricak H, Occhipinti KA, Powell CB, Frankel SD, Stern JL. Ovarian cancer: Staging with CT and MR imaging. Radiology. 1995;197(3):61926.

6. Kurtz AB, Tsimikas JV, Tempany CMC, Hamper UM, Arger PH, Bree RL, et al. Diagnosis and staging of ovarian cancer: comparative values of Doppler and conventional US, CT, and MR imaging correlated with surgery and histopathologic analysis: report of the radiology diagnostic oncology group. Radiology. 1999;212(1):19-27.

7. Woodward PJ, Hosseinzadeh K, Saenger JS. Radiologic staging of ovarian carcinoma with pathologic correlation. Radiographics. 2004;24(1):225-46.

8. Javitt MC, Fleischer AC, Andreotti RF, Bohm-Velez M, Horrow MM, Hricak H, et al. Staging and followup of ovarian cancer. Am Coll Radiol. 2005;12(3):23-6.

9. 9. Jung SE, Lee JM, Rha SE, Byun JY, Jung JI, Hahn ST. CT and MR imaging of ovarian tumors with emphasis on differential diagnosis. RadioGraphics 2002; 22:1305-1325.

10. Yamamoto $\mathrm{Y}$, Yamada R, Oguri H, Maeda N, Fukaya T. Comparison of four malignancy risk indices in the preoperative evaluation of patients with pelvic masses. Eur J Obstet Gynaecol Reprod Biol. 2009; 144:163-7.

11. Iyer VR, Lee SI. MRI, CT, and PET/CT for ovarian cancer detection and adnexal lesion characterization. Am J Roentgenol. 2010;194(2):311-21.

12. Anton C, Carvalho FM, Oliveira EI, Maciel GAR, Baracat EC, Carvalho JP. A comparison of CA125, HE4, risk ovarian malignancy algorithm (ROMA), and risk malignancy index (RMI) for the classification of ovarian masses. Clinics. 2012;67(5):437-41.

13. Liu J, Xu Y, Wang J. Ultrasonography, computed tomography and magnetic resonance imaging for diagnosis of ovarian carcinoma. Eur J Radiol. 2007;62(3):328-34. 
14. Fatma Ferda Verit, Mustafa Pehlivan. Transvaginal ultrasound and computed tomography combined with Ca-125 determinations in preoperative evaluation of ovarian masses in premenopausal women. Harran Üniversitesi Tip Fakültesi Dergisi. 2007;4(2):50-4.

15. Menon U, Gentry-Maharaj A, Hallett R, Ryan A, Burnell M, Sharma A, et al. Sensitivity and specificity of multimodal and ultrasound screening for ovarian cancer, and stage distribution of detected cancers: results of the prevalence screen of the UK collaborative trial of ovarian cancer screening (UKCTOCS). Lancet Oncol. 2009;10(4):327-40.

16. Firoozabadi RD, Zarchi MK, Mansurian HR, Moghadam BR, Teimoori S, Naseri A. Evaluation of diagnostic value of CT scan, physical examination and ultrasound based on pathological findings in patients with pelvic masses. Asian Pac J Cancer Prevent. 2011;12(7):1745-7.

17. Kaijser J, Bourne T, Valentin L, Sayasneh A, Van Holsbeke C, Vergote I, et al. Improving strategies for diagnosing ovarian cancer: a summary of the international ovarian tumor analysis (IOTA) studies. Ultrasound Obstet Gynaecol. 2013;41(1):9-20.

18. Hafeez S, Sufian S, Beg M, Hadi Q, Jamil Y, Masroor I. Role of ultrasound in characterization of ovarian masses. Asian Pac J Cancer Prevent. 2013;14(1):603-6.
19. Mubarak F, Alam MS, Akhtar W, Hafeez S, Nizamuddin N. Role of multidetector computed tomography (MDCT) in patients with ovarian masses. Int J Women's Health. 2011;3(1):123-6.

20. Kurtz AB, Tsimikas JV, Tempany CMC, Hamper UM, Arger PH, Bree RL, et al. Diagnosis and staging of ovarian cancer: comparative values of Doppler and conventional US, CT, and MR imaging correlated with surgery and histopathologic analysis: report of the radiology diagnostic oncology group. Radiology. 1999;212(1):19-27.

21. Kinkel K, Lu Y, Mehdizade A, Pelte MF, Hricak H. Indeterminate ovarian mass at US: incremental value of second imaging test for characterization - metaanalysis and Bayesian analysis. Radiology. 2005;236:85-94.

22. Redman C, Duffy S, Bromham N, Francis K. Guidelines: recognition and initial management of ovarian cancer: summary of NICE guidance. BMJ. 2011;342:7804.

DOI: $10.5455 / 2320-1770 . \mathrm{ij} \operatorname{cog} 20141210$

Cite this article as: Moideen N, Hebbar SS, Rai L, Guruvare S, Adiga P. Comparison of CA-125, conventional ultrasound and $\mathrm{CT}$ imaging in diagnosis and staging of ovarian cancer correlated with surgicopathological findings. Int J Reprod Contracept Obstet Gynecol 2014;3:924-30. 